\title{
Effects of Anthracene Doping Ratio and UV Irradiation Time on Photo-Fries Rearrangement of Polycarbonate
}

\author{
Asrar Abdulmunem Saeed ${ }^{*}$ \\ Farah Jawad Kadhum ${ }^{1}$ \\ Mahasin F. Hadi Al- Kadhemy \\ Zainab Jasim Neamah ${ }^{2}$
}

Received 21/9/2019, Accepted 16/2/2020, Published 23/6/2020

This work is licensed under a Creative Commons Attribution 4.0 International License.

\begin{abstract}
:
Thin films of pure polycarbonate (PC) with anthracene doping PC films for different doping ratios (10, $20,30,40,50$ and $60 \mathrm{ml}$ ) were prepared by using a casting method. The influence of anthracene doping ratio on photo-fries rearrangement of polycarbonate was systematic investigated. Furthermore, pure PC and anthracene doping PC films were irradiated via UV light at a wavelength $(254 \mathrm{~nm})$ for different periods $(5$, 240, 288, and $360 \mathrm{hrs}$ ). The photo-fries rearrangement occurring in pure PC and anthracene doping PC films were monitored using UV and FTIR spectroscopies. The photo-fries rearrangement leads to scission the carbonate linkage and formation phenylsalicylate and dihydroxybenzophenes. The result of the UV spectrum confirms disappear of polycarbonate peaks, while phenylsalicylate and dihydroxybenzophenone peaks appear at $(320 \mathrm{~nm})$ and $(360 \mathrm{~nm})$, respectively. The formation of a dihydroxybiphenyl compound reveals when the UV peak distinguishes at $(340 \mathrm{~nm})$. FTIR spectroscopy supported forms of phenylsalicylate and dihydroxybenzophenone compounds which appear in carbonyl region at $\left(1689 \mathrm{~cm}^{-1)}\right.$ and $\left(1630 \mathrm{~cm}^{-1)}\right.$, respectively. It founds that anthracene accelerates the photo-fries rearrangement of polycarbonate in the anthracene doping PC films because anthracene leads to formation of excited singlet state oxygen $\left({ }^{1} \mathrm{O}_{2}\right)$. Singlet oxygen $\left({ }^{1} \mathrm{O}_{2}\right)$ leads to the formation of a hydro peroxide, which could decompose and cause to chain scission and formation of a terminal of a carbonyl group. The presence of the carbonyl groups in the polymer makes it photo-labile, also warns that the polymer is vulnerable to deterioration.
\end{abstract}

Key words: Anthracene, Effect of doping ratio, FTIR Spectrum, Photo-Fries rearrangement, Polycarbonate.

\section{Introduction:}

Polycarbonate is a kind of polyester where the carbonate ester groups have been connected with an aromatic group (1-4). The basic chemical structure of polycarbonate is shown in Fig. 1, and the name of polycarbonate came from its carbonate backbone $(5,6)$. When polycarbonate irradiation with UV lights at short wavelength $(254 \mathrm{~nm})$ the photo-fries rearrangement is taken place (7). The UV irradiation leads to scission the carbonate linkage and the formation of two free radicals. These free radicals are rearranged in order to form phenylsalicylate and dihydroxybenzophenone, as well as another group such as dihydroxybiphenyl compounds.

\footnotetext{
Department of Physics, College of Science, Mustansiriyah University, Baghdad, Iraq

${ }^{2}$ Department of Physics, College of Education for Pure Science - Ibn Al-Haitham, University of Baghdad, Baghdad, Iraq.

*Corresponding

dr.asrar@uomustansiriyah.edu.iq

*ORCID ID: http://orcid.org/0000-0003-4677-7598
}

Furthermore, the photo-fries products can also be photo-oxidation to product the secondary and tertiary product of lower molecular weight $(6$, $8)$.

Anthracene is a polycyclic aromatic hydrocarbon (PAH) consisting of three benzene rings (9). Excited state polycyclic aromatic hydrocarbon (PAH) can act as a photosensitizer. That is commonly used in polymer chemistry; in reactions such as photo polymerization, photo crosslinking, and photo degradation (10). Photosensitization by a chemical can be result in formation of excited singlet state oxygen $\left({ }^{1} \mathrm{O}_{2}\right)$ (11).The reaction steps concerned in photosensitization are as follow (12):

The sensitizer molecule in the ground state $\left(S_{0}\right)$ absorbs a photon to reach the first singlet excited state $\left({ }^{1} \mathrm{~S}^{*}\right)$ eq. 1 :

$$
\mathrm{S}_{0}+\mathrm{h} v \rightarrow{ }^{1} \mathrm{~S}^{*} \ldots 1
$$

Intersystem crossing generate the excited triplet $\left({ }^{3} \mathrm{~S}^{*}\right)$ eq. 2 : 
The excited triplet $\left({ }^{3} \mathrm{~S}^{*}\right)$ can be quenched by a stable oxygen molecule to form the ground state sensitizer $\left(\mathrm{S}_{0}\right)$ and $\left({ }^{1} \mathrm{O}_{2}\right)$ eq. 3 :

$$
{ }^{3} \mathrm{~S}^{*}+\mathrm{O}_{2} \rightarrow \mathrm{S}_{0}+{ }^{1} \mathrm{O}_{2}
$$

Singlet oxygen $\left({ }^{1} \mathrm{O}_{2}\right)$ exhibits several particular reactions. One of the most important reactions of singlet oxygen in photodegradation of polymers is the formation of a hydro-peroxide. This product could decompose and cause to chain scission and formation of a terminal of a carbonyl group (13).

The presence of carbonyl groups in a degraded polymer indicates that oxidation has taken place and warns that the material is vulnerable to further deterioration because they are photo-labile (14).

Rivaton et al., (15) studied a comparison of the photochemical and thermal degradation of thin films of bisphenol-A polycarbonate and trimethylcyclohexane-polycarbonate. The results reveal that thin films with a thickness of $(20 \mu \mathrm{m})$ were obtained by evaporation of polymer solution in $\mathrm{CHCI}_{3}$ compound. It founded that when samples irradiation at short wavelength $(254 \mathrm{~nm})$, the photofries rearrangement was taken place and led to form phenylsalicylate and dihydroxybenzophenone composites. Since, the UV bands of phenylsalicylate and dihydroxybenzophenone seemed at $(320 \mathrm{~nm})$ and $(355 \mathrm{~nm})$, respectively. Examine of FTIR spectra confirmed that formation of phenyl salicylate and dihydroxybenzophenone in carbonyl region at $\left(1689 \mathrm{~cm}^{-1}\right)$ and $\left(1629 \mathrm{~cm}^{-1}\right)$, respectively.

Moreover, Salh (16), investigated the spectroscopic properties of HALS (HALS: Tinuvin 770 and Tinuvin 123) doped polycarbonate films with a thickness of $(2 \mathrm{~mm})$. The UV irradiation of as- grown samples is achieved by using UV source for (48 hours) under dry condition (i.e. room relative humidity). The distance between the lamp and the sample is $(28 \mathrm{~cm})$. The UV-Vis spectroscopy showed that the absorbance for wavelengths below $(400 \mathrm{~nm})$ is increasing with increasing (Tinuvin 770) concentration. Two peaks were appeared at wavelengths $(320 \mathrm{~nm})$ and (355 $\mathrm{nm})$, which are attributed to phenylsalicylate and dihydroxybenzophenone composites, respectively.

The major aim of the present work is to investigate the photo-fries rearrangement of pure PC and anthracene doping PC films for different doping ratios 10, 20, 30, 40, 50 and $60 \mathrm{ml}$. In addition, study the effect of anthracene addition on the photo-fries rearrangement of polycarbonate compound. The product material could be beneficial for various applications such as safety helmets, lenses light globes and base for photographic film.

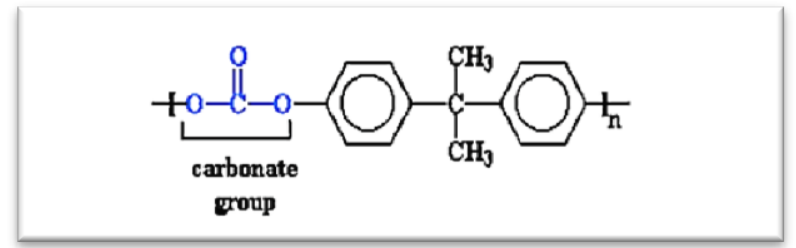

Figure 1. The basic chemical structure of polycarbonate (PC) compound (19)

\section{Materials and Method:}

Polycarbonate with common brand name Lexan (provided by Sabic company) and anthracene with the chemical formula $\left(\mathrm{C}_{14} \mathrm{H}_{10}\right)$ (Treated by the company Chemical Point) used in this work. Pure PC films were doping via different ratios of anthracene include 10, 20, 30, 40, 50 and $60 \mathrm{ml}$ by using the casting technique. In briefly, pure PC film was prepared by dissolve $0.3 \mathrm{~g}$ of $\mathrm{PC}$ in $10 \mathrm{ml}$ Chloroform. Then, the as-synthesis PC solutions cast onto glass petri dish with a diameter $10 \mathrm{~cm}$ and leave it dry at room temperature for $24 \mathrm{hrs}$ to acquire homogeneous pure PC films. Furthermore, the anthracene solution with a concentration of $\left(1 \times 10^{-4} \mathrm{~mol} / \mathrm{L}\right)$ was prepared according to the procedure explained in the previous study (17). Different ratios of anthracene solution 10, 20, 30, 40, 50 and $60 \mathrm{ml}$ were added to the PC solution as mentioned earlier and mixed very well for $30 \mathrm{~min}$. The mixture cast onto a glass petri dish with $10 \mathrm{~cm}$ diameter and left to dry at room temperature for (24 hrs) to get homogeneous doping PC films. Irradiate aging was carried out by UV-cabinet using a mercury lamp (Leicarm 2145; Germany). The asprepared pure PC film and anthracene doping PC film were irradiated by UV light at wavelength 254 $\mathrm{nm}$ for various periods 5, 240, 288, and $360 \mathrm{hrs}$. Finally, the UV-Visible spectrophotometer type (T70/T80 Series UV/VIS Spectrometer) and FTIR spectroscopy (FTIR-600 biotech engineering management) used to characterize the photo-fries rearrangement products.

\section{Results and Discussions: Absorption Spectrum}

The absorption spectra of pure PC film as well as, PC films doping by the various ratio of anthracene 10, 20,30, 40,50 and $60 \mathrm{ml}$ were examined as presented in Fig. 2. Results show that the spectrum of pure PC film exhibit two major peaks at $305 \mathrm{~nm}$ and $345 \mathrm{~nm}$, it's referring to the carbonyl group of polycarbonate. Meanwhile, anthracene doping PC films exhibited red-shift in absorption peaks at wavelengths $360 \mathrm{~nm}$ and 380 $\mathrm{nm}$, respectively. These results could be attributed to the anthracene compound. 


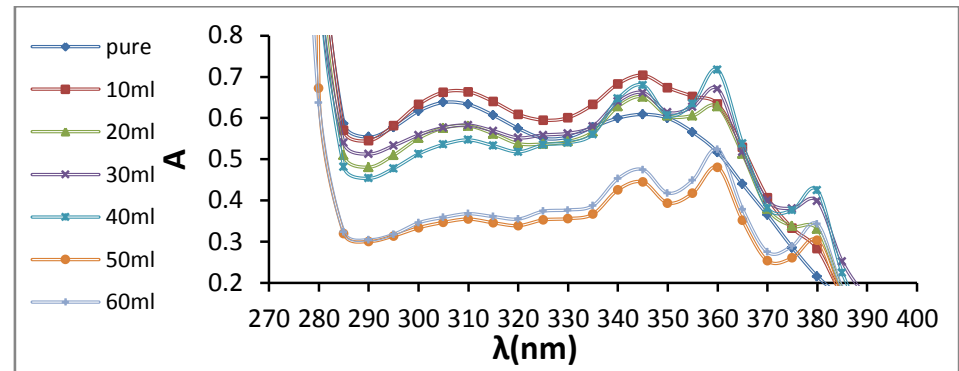

Figure 2. Absorption spectra of pure PC film and anthracene doped PC films for different doping ratio

The influence of UV radiation $(254 \mathrm{~nm})$ for irradiation times in the range of $(5,240,288,360$ hrs) on the UV-Vis absorption properties of asgrown pure PC film and PC films doping with anthracene for the different ratio as illustrated in Table 1.

Figure 3 shows the effect of UV irradiation at $254 \mathrm{~nm}$ for 5 hours on the absorption properties of pure PC film and anthracene doping PC films. Due to the irradiation process, it seems that the second peak of polycarbonate at $(345 \mathrm{~nm})$ disappear for pure PC film, which could be attributed to the variation in the structure characteristics. Spectra analyses of anthracene doping PC films for doping ratio 10,20 and $30 \mathrm{ml}$ were exhibited similar behavior. Besides that, a single absorption peak appears at the wavelength $325 \mathrm{~nm}$ of anthracene doping PC films for doping ratio 50 and $60 \mathrm{ml}$, which refers to the formation of phenylsalicylate $(15,16)$.

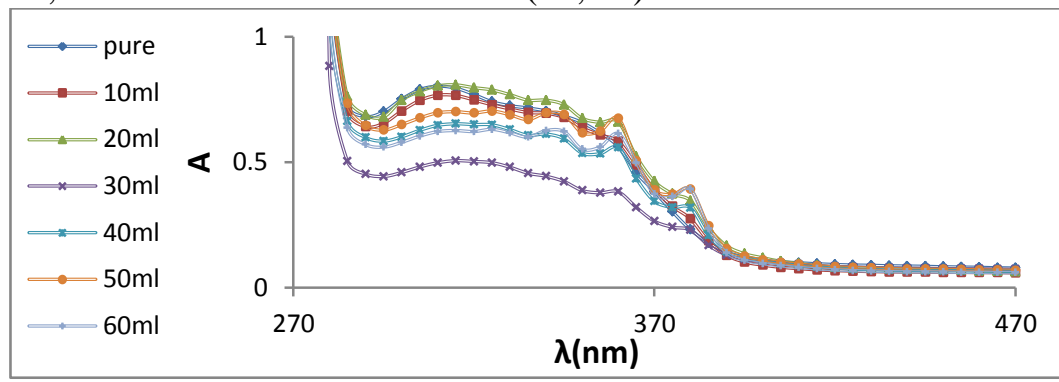

Figure 3. Effect of UV radiation on the absorption spectrum of pure PC film and anthracene doping PC films for different doping ratio for irradiation time $(5 \mathrm{hrs})$

For further study, the UV irradiation effect on the absorption spectra of pure PC and anthracene doping PC films for irradiation time $240 \mathrm{hrs}$ was also examined as shown in Fig. 4. Figure 4 reveals that the polycarbonate absorption peaks around 305 $\mathrm{nm}$ and $345 \mathrm{~nm}$ were disappeared, that endorsed to scission of carbonate linkage and phenylsalicylate appears at the wavelength $320 \mathrm{~nm}(15,16)$. Furthermore, absorption peaks of anthracene at 360 $\mathrm{nm}$ and $380 \mathrm{~nm}$ were vanished due to the irradiation process for $(240 \mathrm{hrs})$.

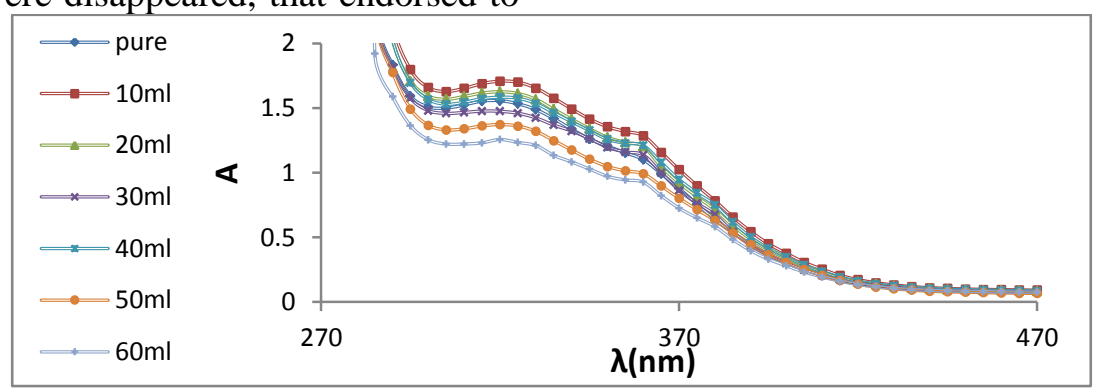

Figure 4. Influence of $U V$ radiation on absorption spectra of pure PC film and anthracene doping PC films for altered doping ratio for irradiation time $(240 \mathrm{hrs})$

Figure 5 shows the absorption spectra of UV irradiation for $288 \mathrm{hrs}$ of pure PC film and anthracene doping PC films. The absorption peak of a dihydroxybenzophenone compound at a wavelength $360 \mathrm{~nm}$ in anthracene doping PC film for doping ratio $60 \mathrm{ml}$ was toward to appear (15, 16), as confirmed in Fig. 5. Due to the photo-fries rearrangement in PC film; this leads to the construction of phenylsalicylate and dihydroxybenzophenone. Based on the UV irradiation, the oxygen from the weak $\mathrm{C}-\mathrm{O}$ bond reorganizes its position to shape a stronger $\mathrm{O}-\mathrm{H}$ bond which resulting in phenylsalicylate form. Furthermore, when the oxygen of the C-O group in 
phenylsalicylate structure suffer from further results in a dihydroxybenzophenone configuration. reorganization to form strong $\mathrm{O}-\mathrm{H}$ bond then it
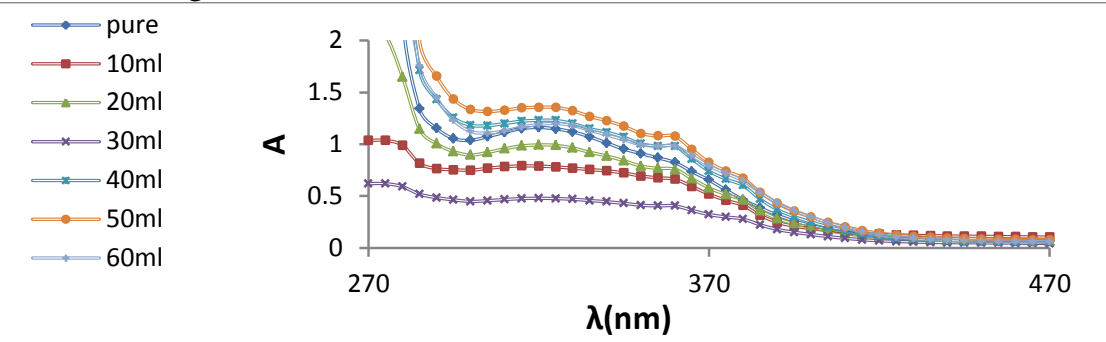

Figure 5. The UV irradiation effect (wavelength $254 \mathrm{~nm}$ for $288 \mathrm{hrs}$ ) on absorption spectra of pure PC film and anthracene doping PC films for various doping ratio

Moreover, the influence of irradiation time (360 hrs) via UV radiation on the absorption characteristics of pure PC sample and anthracene doping PC samples were displayed in Fig. 6. The dihydroxybenzophenone compound appears in anthracene doping PC films for doping ratio $30 \mathrm{ml}$, $40 \mathrm{ml}, 50 \mathrm{ml}$, and $60 \mathrm{ml}$ at wavelength $360 \mathrm{~nm}(15$,
16). As well as, the new absorption peak appears at wavelength $340 \mathrm{~nm}$ in anthracene doping PC film for doping ratio $60 \mathrm{ml}$. Formation of phenylsalicylate and dihydroxybenzophenone compounds refers to the photo-fries rearrangement is take place (15).
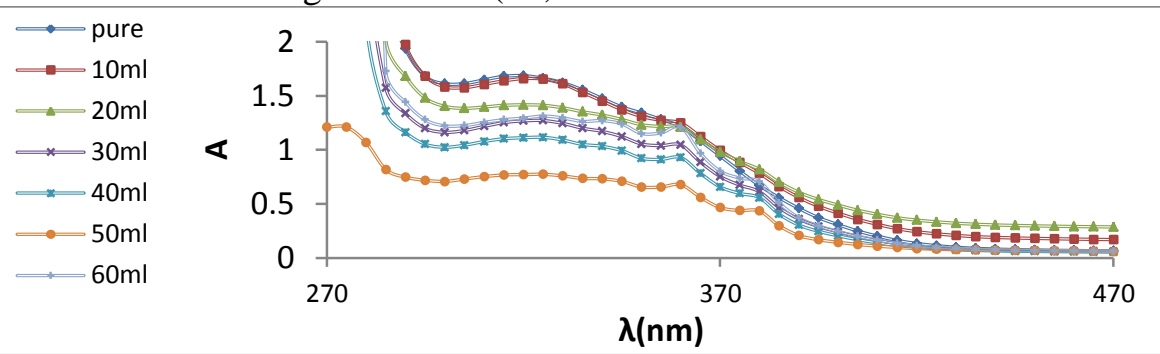

Figure 6. The influence of irradiation time $(360 \mathrm{hrs})$ via $\mathrm{UV}$ radiation on the absorption characteristics of pure PC sample and anthracene doping PC samples.

Table 1. The absorption peaks for un-irradiated and irradiated pure PC and anthracene doping PC

films with UV radiation at wavelength $(254 \mathrm{~nm})$

\begin{tabular}{|c|c|c|c|c|c|c|c|c|}
\hline \multirow{2}{*}{ Time } & & & \multicolumn{6}{|c|}{ Doping Ratio of anthracene -PC Films } \\
\hline & & $\mathbf{P C}$ & $10 \mathrm{ml}$ & $20 \mathrm{ml}$ & $30 \mathrm{ml}$ & $40 \mathrm{ml}$ & $50 \mathrm{ml}$ & 60ml \\
\hline \multirow{11}{*}{$0 \mathrm{hrs}$} & $\lambda_{\max }(\mathrm{nm})$ & 305 & 310 & 310 & 310 & 310 & 310 & 310 \\
\hline & Absorbance & 0.638 & 0.664 & 0.581 & 0.583 & 0.547 & 0.355 & 0.368 \\
\hline & $\lambda_{\max }(\mathbf{n m})$ & 345 & 345 & 345 & 345 & 345 & 345 & 345 \\
\hline & Absorbance & 0.609 & 0.704 & 0.652 & 0.662 & 0.68 & 0.445 & 0.475 \\
\hline & $\lambda_{\max }(\mathbf{n m})$ & & & 360 & 360 & 360 & 360 & 360 \\
\hline & Absorbance & & & 0.628 & 0.671 & 0.717 & 0.481 & 0.524 \\
\hline & $\lambda_{\max }(\mathbf{n m})$ & & & & 380 & 380 & 380 & 380 \\
\hline & Absorbance & & & & 0.399 & 0.425 & 0.304 & 0.343 \\
\hline & $\lambda_{\max }(\mathbf{n m})$ & 310 & 310 & 315 & 315 & 315 & 315 & 315 \\
\hline & Absorbance & 0.803 & 0.767 & 0.808 & 0.506 & 0.653 & 0.701 & 0.626 \\
\hline & $\lambda_{\max }(\mathbf{n m})$ & & & & & & 325 & 325 \\
\hline \multirow{8}{*}{$5 \mathrm{hrs}$} & Absorbance & & & & & & 0.704 & 0.631 \\
\hline & $\lambda_{\max }(\mathbf{n m})$ & & & & & 340 & 340 & 340 \\
\hline & Absorbance & & & & & 0.612 & 0.696 & 0.626 \\
\hline & $\lambda_{\max }(\mathbf{n m})$ & & & 360 & 360 & 360 & 360 & 360 \\
\hline & Absorbance & & & 0.66 & 0.382 & 0.558 & 0.675 & 0.614 \\
\hline & $\lambda_{\max }(\mathbf{n m})$ & & & & & & 380 & 380 \\
\hline & Absorbance & & & & & & 0.392 & 0.392 \\
\hline & $\lambda_{\max }(\mathbf{n m})$ & 320 & 320 & 320 & 315 & 320 & 320 & 320 \\
\hline $240 \mathrm{hrs}$ & Absorbance & 1.557 & 1.708 & 1.626 & 1.477 & 1.584 & 1.373 & 1.257 \\
\hline \multirow{4}{*}{$288 \mathrm{hrs}$} & $\lambda_{\max }(\mathbf{n m})$ & 320 & 315 & 320 & 320 & 320 & 320 & 325 \\
\hline & Absorbance & 1.163 & 0.792 & 0.994 & 0.479 & 1.232 & 1.358 & 1.201 \\
\hline & $\lambda_{\max }(\mathbf{n m})$ & & & & & & & 360 \\
\hline & Absorbance & & & & & & & 0.983 \\
\hline \multirow{6}{*}{$360 \mathrm{hrs}$} & $\lambda_{\max }(\mathbf{n m})$ & 320 & 320 & 320 & 325 & 325 & 325 & 325 \\
\hline & Absorbance & 1.686 & 1.659 & 1.416 & 1.271 & 1.116 & 0.774 & 1.312 \\
\hline & $\lambda_{\max }(\mathbf{n m})$ & & & & & & & 340 \\
\hline & Absorbance & & & & & & & 1.27 \\
\hline & $\lambda_{\max }(\mathbf{n m})$ & & & & 360 & 360 & 360 & 360 \\
\hline & Absorbance & & & & 1.045 & 0.929 & 0.678 & 1.209 \\
\hline
\end{tabular}




\section{FTIR Spectra Analysis}

Figure 7 shows the FTIR spectra of pure PC and anthracene doping PC films with different doping ratios $10,20,30,40,50$ and $60 \mathrm{ml}$. It can be easily seen that no observable peaks are seen to be appearing or disappearing but an only slight change in the position of bonds in anthracene doping PC films for different doping ratios.

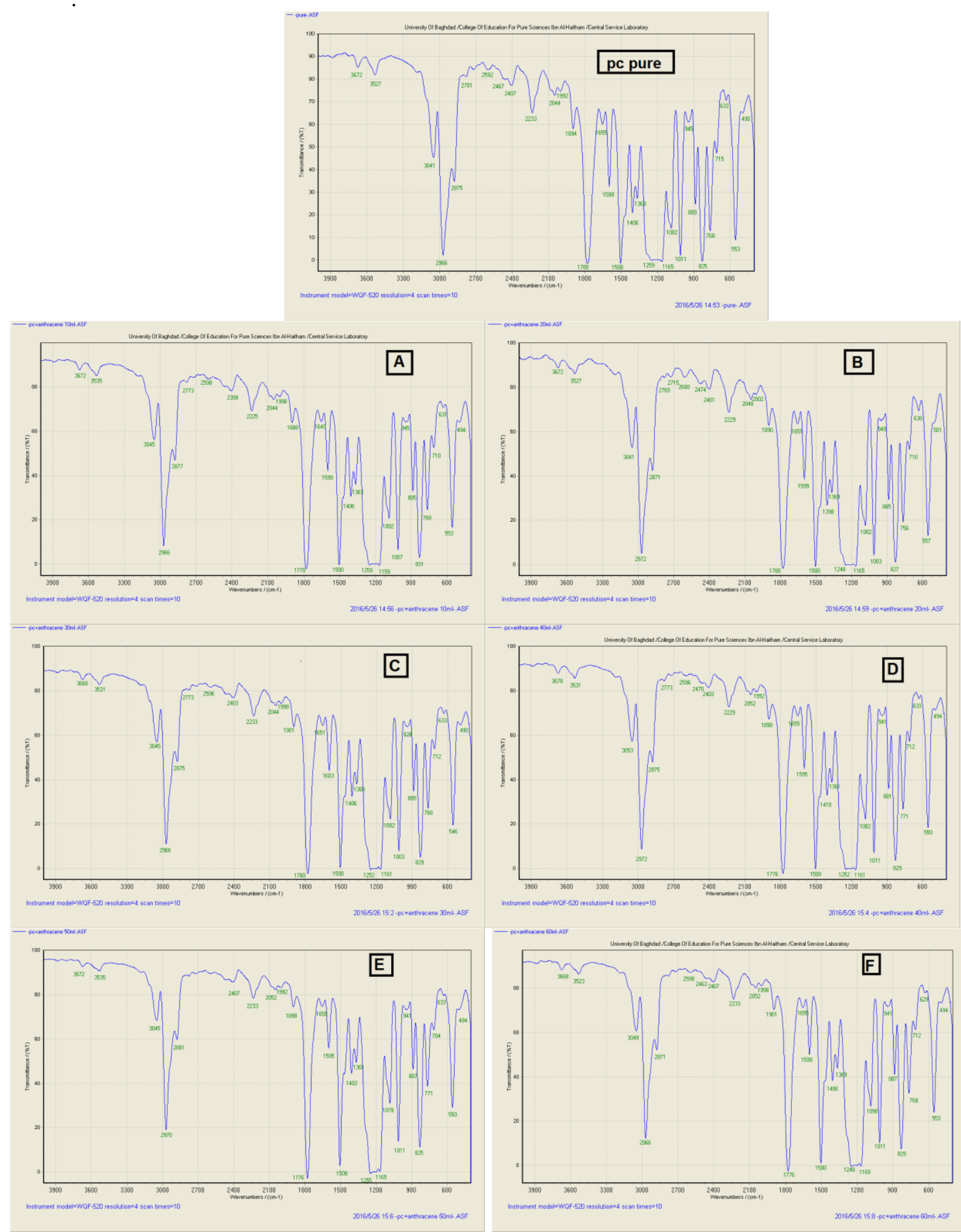

Figure 7. FTIR spectra of pure PC and anthracene doping PC films for different doping ratios:

(A) $10 \mathrm{ml}$, , (B) $20 \mathrm{ml}$, (C) $30 \mathrm{ml}$, (D) $40 \mathrm{ml}$, (E) $50 \mathrm{ml}$ and (F) $60 \mathrm{ml}$

The UV irradiation influence at the wavelength $254 \mathrm{~nm}$ and irradiation time $5 \mathrm{hrs}$ on FTIR spectra of pure PC and anthracene doping PC films for various doping ratios were presented in Fig. 8. The phenylsalicylate appears in the $\mathrm{C}=\mathrm{O}$ stretching region at $1685 \mathrm{~cm}^{-1}$ of anthracene doping 
PC films for doping ratio (50 and $60 \mathrm{ml})$, this result supports by literature (15).

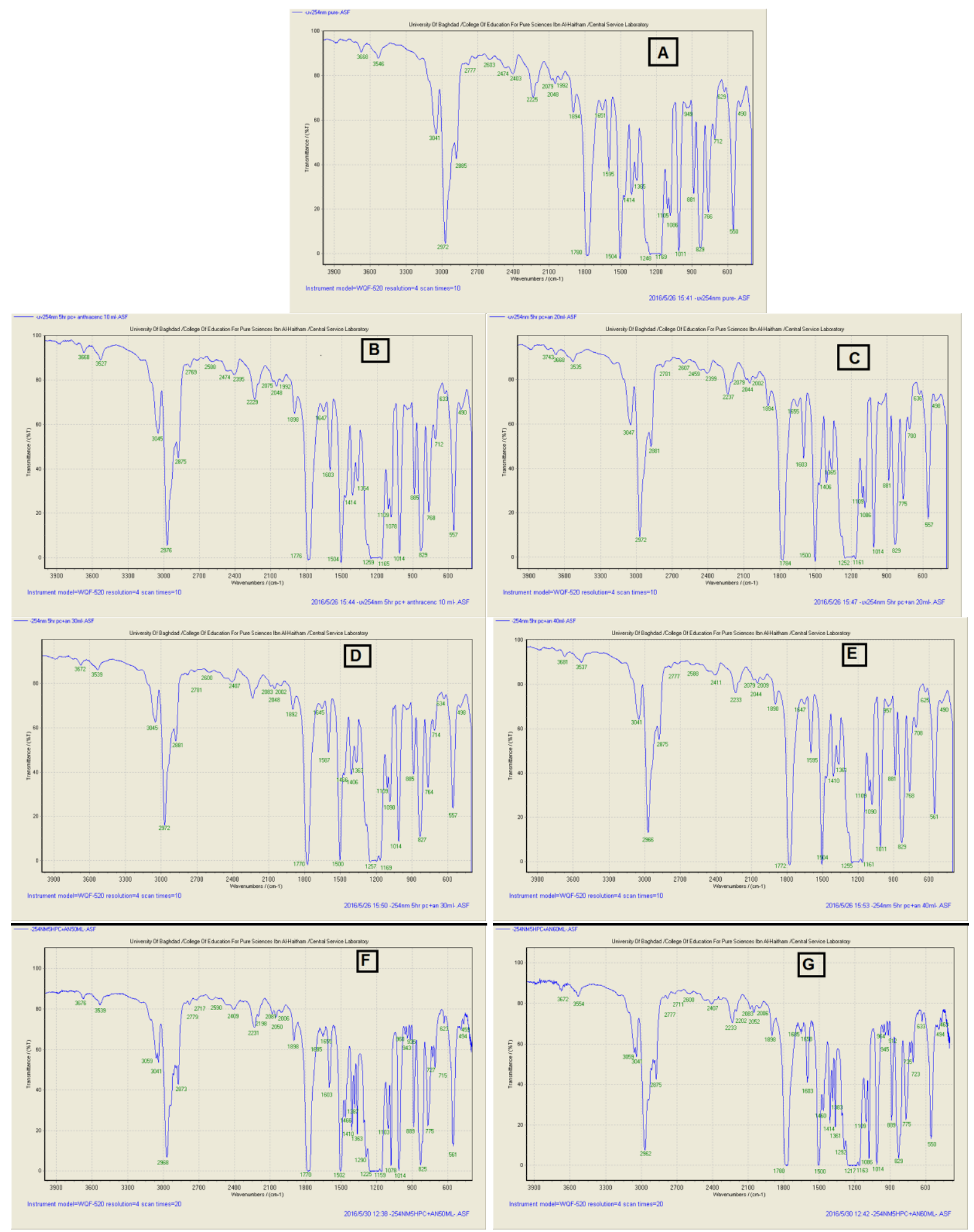

Figure 8. The UV irradiation influence at wavelength $(254 \mathrm{~nm})$ and irradiation time ( $5 \mathrm{hrs})$ on FTIR spectra of (A) pure PC; and anthracene doping PC films for various doping ratio (B) $10 \mathrm{ml},(\mathrm{C}) 20 \mathrm{ml}$, (D) $30 \mathrm{ml}$, (E) $40 \mathrm{ml}$, (F) $50 \mathrm{ml}$ and (G) $60 \mathrm{ml}$

The effect of UV radiation at the wavelength $254 \mathrm{~nm}$ on FTIR spectra of pure PC and anthracene doping PC films for different doping ratios for 240 hrs shows in Fig. 9. The phenylsalicylate appear in pure PC at $\left(1685 \mathrm{~cm}^{-1}\right)$ and in anthracene doping PC films at $1689 \mathrm{~cm}^{-1}$ for doping ratio 10 and $40 \mathrm{ml}$ as well as at $1682 \mathrm{~cm}^{-1}$ for doping ratio 20 and 30 $\mathrm{ml}$ and around $1685 \mathrm{~cm}^{-1}$ for doping ratio 50 and $60 \mathrm{ml} \mathrm{(15).}$ 


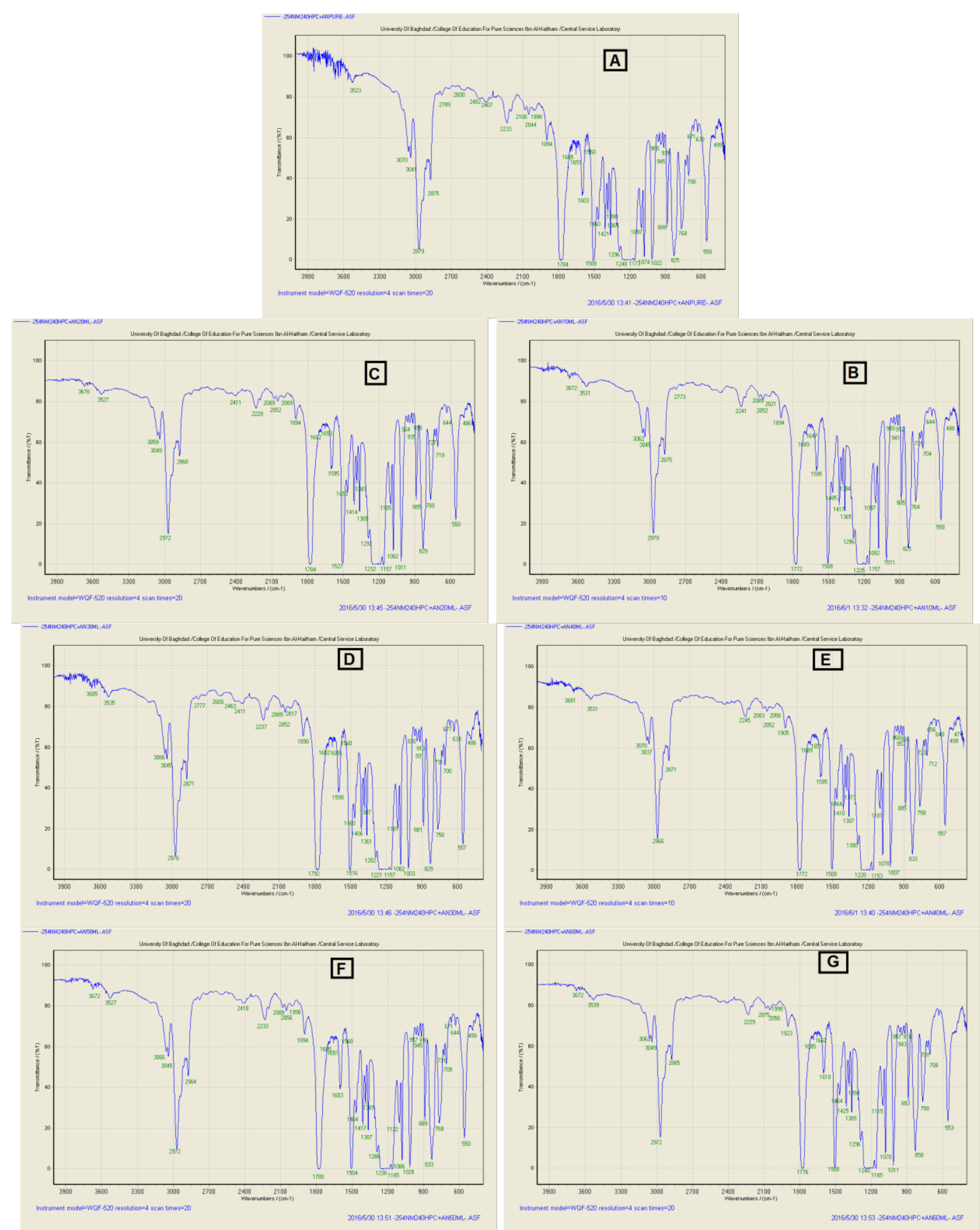

Figure 9. The effect of UV light at wavelength $(254 \mathrm{~nm})$ for $(240 \mathrm{hrs})$ on FTIR spectra of (A) pure PC sample; and PC/anthracene films for different doping ratio (B) $10 \mathrm{ml},(C) 20 \mathrm{ml}$, (D) $30 \mathrm{ml}$, (E) $40 \mathrm{ml}$, (F) $50 \mathrm{ml}$ and (G) $60 \mathrm{ml}$

Furthermore, the special effects of UV radiation at the wavelength $254 \mathrm{~nm}$ for $288 \mathrm{hrs}$ on FTIR spectra of pure PC film and anthracene doping PC films for diverse doping ratio demonstrated in Fig. 10. The phenylsalicylate complex appears in pure PC at $1685 \mathrm{~cm}^{-1}$ and in anthracene doping PC films at $1685 \mathrm{~cm}^{-1}$ for doping ratio 10 and $20 \mathrm{ml}$. While, FTIR peaks at $1689 \mathrm{~cm}^{-1}$ were revealed for doping ratio 30,50 , and $60 \mathrm{ml}$ and at $1682 \mathrm{~cm}^{-1}$ for doping ratio $40 \mathrm{ml}$. The dihydroxybenzophenone appears in anthracene doping PC films for doping ratio of $60 \mathrm{ml}$ at 1626 $\mathrm{cm}^{-1}$ as supported in previous study (15). These results can be ascribed to the absorption spectrum of 
a polymer is generally dependent on the chromophores existing in its structure. The presence of a substituent group in a chromophore can shift the absorption band to either shorter wavelength or longer wavelength.
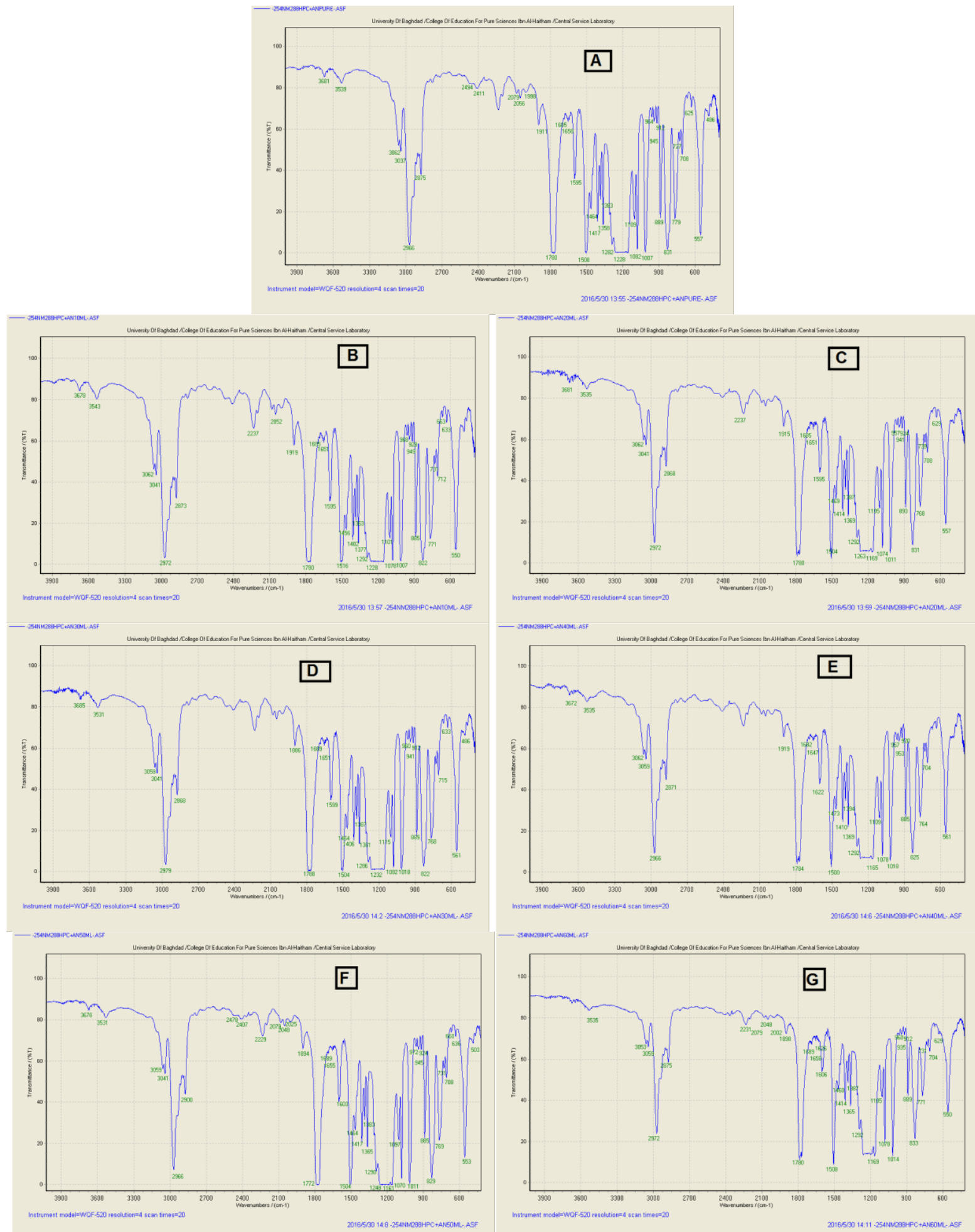

Figure 10. The effect of UV light at wavelength $(254 \mathrm{~nm})$ for $(288 \mathrm{hrs})$ on FTIR spectra of (A) pure PC film; and PC/anthracene films for different doping ratio (B) $10 \mathrm{ml}$, (C ) $20 \mathrm{ml}$, (D) $30 \mathrm{ml}$, (E) $40 \mathrm{ml}$, (F) $50 \mathrm{ml}$ and $(\mathrm{G}) 60 \mathrm{ml}$

The effect of UV radiation at wavelength $254 \mathrm{~nm}$ on FTIR spectra of pure PC film and anthracene doping PC films for different doping ratios for $360 \mathrm{hrs}$ shows in Fig. 11. The phenylsalicylate appears in pure PC film at 1685 $\mathrm{cm}^{-1}$ and in anthracene doping PC films at 1685 
$\mathrm{cm}^{-1}$ for doping ratio $10,20,40,50$, and $60 \mathrm{ml}$. Furthermore, the FTIR spectra in Fig. 11 show a distinguished peak at $1684 \mathrm{~cm}^{-1}$ for the doping ratio $30 \mathrm{ml}$. The dihydroxylbenzophenone perform in anthracene doping PC films at $1635 \mathrm{~cm}^{-1}$ for doping ratio $30 \mathrm{ml}$, and at $1637 \mathrm{~cm}^{-1}$ for doping ratio $40 \mathrm{ml}$ as well as around $1633 \mathrm{~cm}^{-1}$ for doping ratio $60 \mathrm{ml}$ (18). This change in the FTIR peaks position can be attributed as due to the manipulation in the structural properties of the assynthesized material. Where, at $360 \mathrm{hrs}$ longer UV exposures the polymer becomes further photoinstability hence photo-fries reaction is taking place.
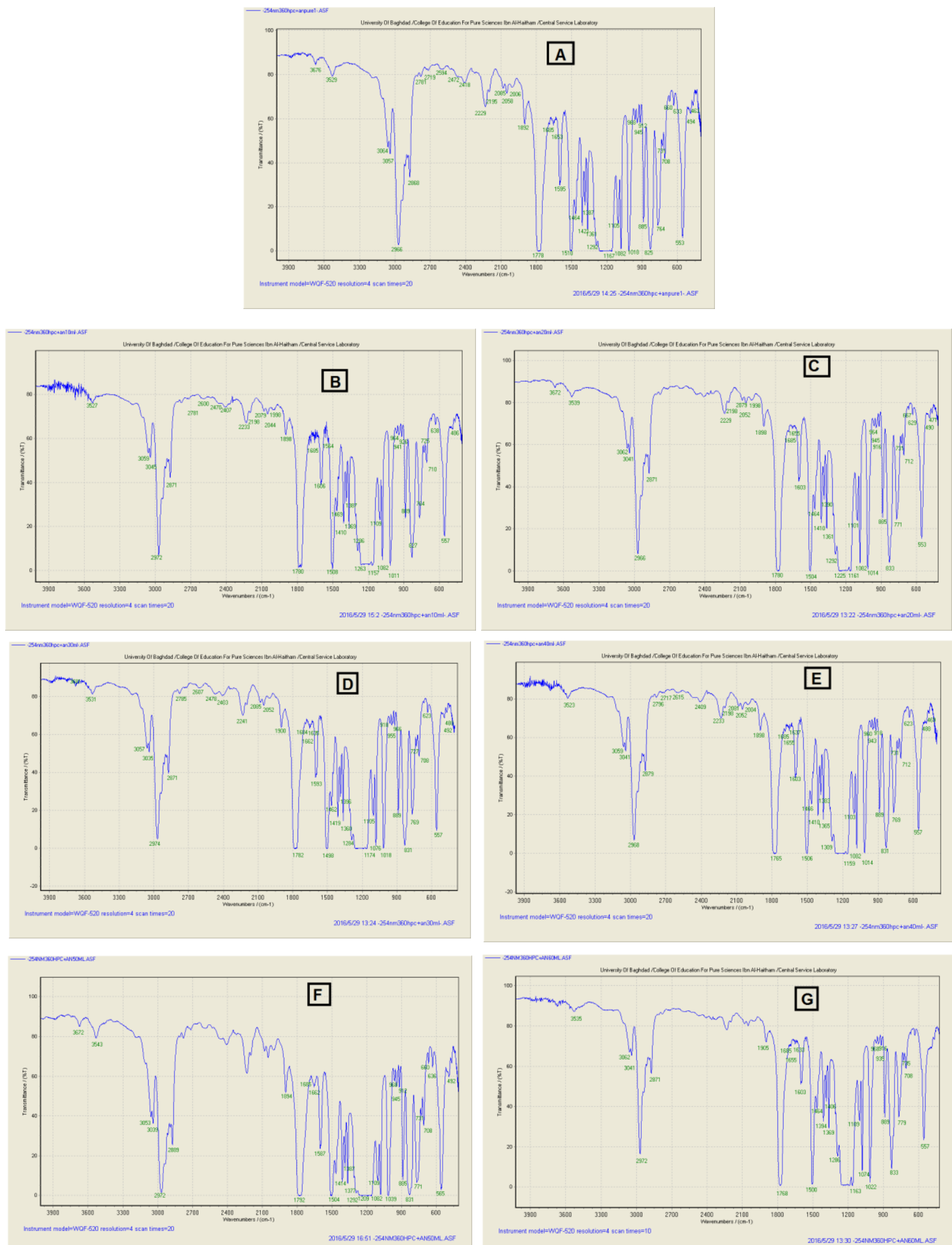

Figure 11. The influence of UV light at wavelength $(254 \mathrm{~nm})$ for $(360 \mathrm{hrs})$ on FTIR spectra: (A) pure PC film; and PC/anthracene films for altered doping ratio, (B)10 ml, (C) $20 \mathrm{ml}$, (D) $30 \mathrm{ml}$, (E) $40 \mathrm{ml}$, (F) $50 \mathrm{ml}$ and (G) $60 \mathrm{ml}$. 


\section{Conclusions:}

Successfully synthesis of pure polycarbonate (PC) and anthracene doping PC films for different doping ratios 10, 20, 30, 40, 50 and 60 $\mathrm{ml}$ was achieved by using cast technique. This study proved that there was a strong influence of UV radiation $254 \mathrm{~nm}$ at various irradiation times 5, 240, 288, and $360 \mathrm{hrs}$ on the absorption spectra of asgrown samples. The results reveal that the formation of phenylsalicylate and dihydroxybenzophenone compounds. Thus, the photo-fries reaction is take place. Furthermore, anthracene doping of PC film with appropriate ratio leads to accelerate the photo-fries rearrangement of polycarbonate in as-grown films. Apportion peaks of as-prepared films of PC and anthracene doping PC films revealed appear and disappeared different absorption peaks depend on UV irradiation time and anthracene doping ratio $10,20,30,40,50$ and $60 \mathrm{ml}$ of films.

\section{Acknowledgments:}

The authors would like to thank Mustansiriyah University for its support in the present work.

\section{Authors' declaration:}

- Conflicts of Interest: None.

- We hereby confirm that all the Figures and Tables in the manuscript are mine ours. Besides, the Figures and images, which are not mine ours, have been given the permission for republication attached with the manuscript.

- Ethical Clearance: The project was approved by the local ethical committee in University of Baghdad.

\section{References:}

1. Markovičová L, Zatkalíková. V. The effect of UV aging on structural polymers. IOP Conference Series: Mater Sci Eng. 2019; 465(1): 012004.

2. Hacıoğlu F, Özdemir T, Kinalır K, Usanmaz A. Possible use of bisphenol-a polycarbonate in radioactive waste embedding. Prog Nucl Energ. 2016; 90: 98-104.

3. Gupta D, Kumar S, KalsiP, Manchanda V, Mittal V. $\gamma$-ray modifications of optical/chemical properties of polycarbonate polymer. WJCMP. 2015; 5(3): 129137.

4. Hareesh K, Sanjeev G. Effects of Radiations on the Properties of Polycarbonate. Springer Series on Polymer and Composite Materials, 2019; chap 9, 293 - 318.

5. Diepens M, Gijsman P. Photodegradation of bisphenol A polycarbonate. Polym. Degrad. Stab, 2007; 92(3): 397- 406.
6. Sabu T, Cvrček L, Horáková M. Non Thermal Plasma Technology for Polymeric Materials Applicationsin Composites, Nanostructured Materials and Biomedical Fields. Application in composites, nanostructured materials, and biomedical fields $1^{\text {st }}$ ed, Elsevier. 2019; 367-407.

7. Diepens M. Photodegradation and stability of bisphenol a polycarbonate in weathering conditions. Eindhoven, Technische Universiteit Eindhoven. 2009;200; 52-65.

8. Tjandraatmadja G, Burn L, Jollands M. The effects of ultraviolet radiation on polycarbonate glazing. Proc. 8th International Conf. On Durability of Building and Construction Materials. Vancouver, Canada. 1999; 30, 884-898.

9. Mackie CJ, Candian A, Huang X, Maltseva EA, Petrignani JO, Omens WJ, et al. The anharmonic quartic force field infrared spectra of three polycyclic aromatic hydrocarbons: Naphthalene, anthracene, and tetracene. J Chem Phys. 2015; 143(22): 224314.

10. Lambert S. Environmental Risk of Polymer and their Degradation Products. UK, University of York. 2013; pp, 13 - 16.

11. Zhang XF, Yang X, Xu B. PET-based bisBODIPY photosensitizers for highly efficient excited triplet state and singlet oxygen generation: tuning photosensitizing ability by dihedral angles. Phys Chem Chem Phys. 2017; 19(36): 24792-24804.

12. Waghmare R, Belsare N, Raghuwanshi F, Shilaskar S. Study of dc electrical conductivity of paranitroaniline doped (1:1) polyvinylchloride and poly (methyl methacrylate) polyblends. Bull Mater Sci, 2007; 30(2): 167-172.

13. Yousif E, Haddad R. Photodegradation and photostabilization of polymers, especially polystyrene. Springer plus, Springer. 2013; 2(1): 398.

14. Halliwell SM. Weathering of plastics glazing materials. UK, Loughborough University, SM Halliwell, 1996; 6 - 15.

15. Rivaton A, Mailhot B, Soulestin J, Varghese H, Gardette J. Comparison of the photochemical and thermal degradation of bisphenol-A polycarbonate and trimethylcyclohexane-polycarbonate. Polym Degrad Stab. 2002; 75(1): 17-33.

16. Salh R. Spectroscopic properties of HALS doped 2 polycarbonate by fluorescence spectroscopy. Parameters, Umeå University, Sweden. 2013; 74, P 75.

17. Saeed A A, kadhum F J, Al-Kadhemy M F H, Neamah Z J. Study the effect of ultraviolet radiation on the optical oroperties of pure polycarbonate and anthracene doping PC films. J. Eng. Appl. Sci. 2018; 13(24): 10245-10253.

18. Hsiao, YC, Harmon JP, Chuang YF, Chiang D, Lee S. Acetone absorption in UV-irradiated polycarbonate. Polym Eng Sci. 2018; 58(7): 1174 1183.

19. Wypych G. Handbook of polymers. Canada, ChemTec Publishing, Elsevier. 2016; 50 -65. 
تاثير نسبة التطعيم بالأثراسين وزمن التشعيع بالأشعة فوق البنفجية على إعادة ترتيب تفاعلات الفوتو فريز للبولي كاربونيت

محاسن فاضل هادي 1

زينب جاسم نعمة2

اسرار عبدالمنعم سعيد1

1 1 قسم الفيزياء، كلية العلوم، الجامعة المستتصلرية، بغداد، العراق.

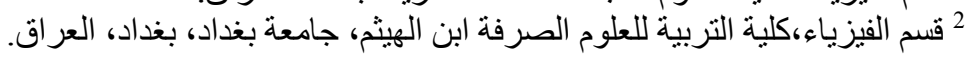

تم في هذه الدر اسة تحضير افلام نقية من البولي كاربونيت (PC) و افلام اخرى من البولي كاربونيت مطعمة بنسب مختلفة من مادة

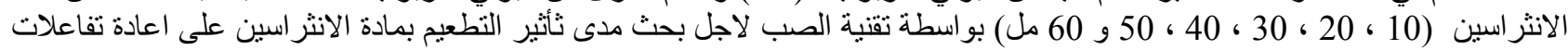

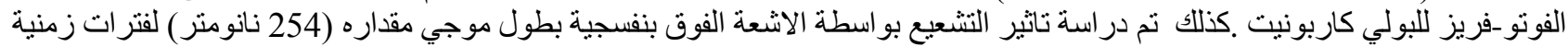

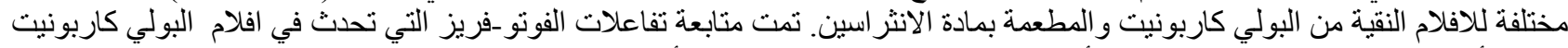

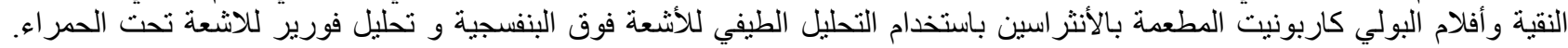

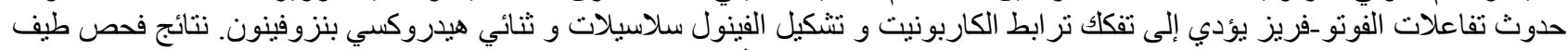

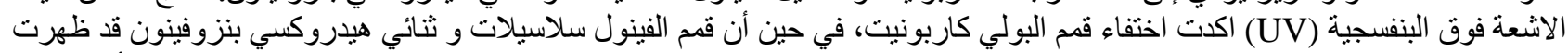

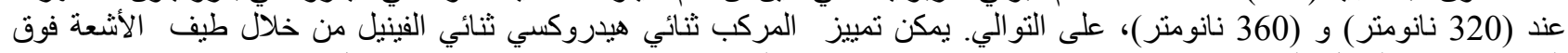

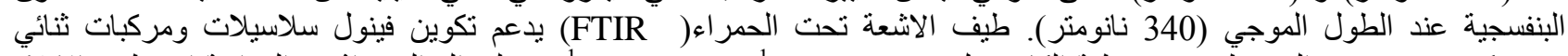

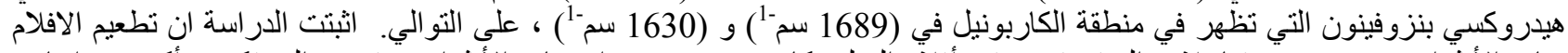

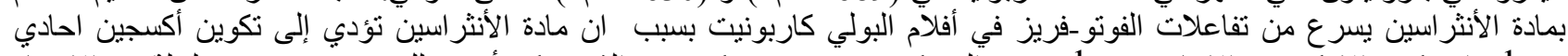

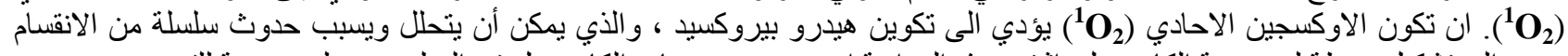

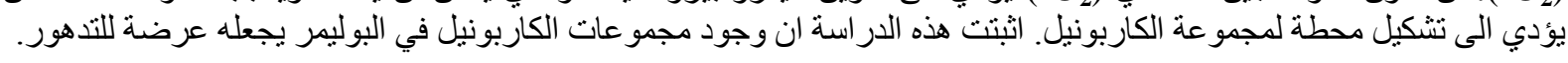

الكلمات المفتاحية: الانثر اسين، ناثير نسبة التطعيم، طيف الاشعة تحت الحمراء، بولي كابونيت، تفاعلات الفوتو-فريز. 